\title{
Nonlinear Complexity and Spectral Analyses of Heart Rate Variability in Medicated and Unmedicated Patients with Schizophrenia'
}

\author{
L.R. Mujica-Parodia Vikram Yeragani $^{\mathrm{b}}$ Dolores Malaspinac, \\ a Departments of Biomedical Engineering and Psychiatry, Laboratory for the Study of Emotion and Cognition, \\ School of Medicine at the State University of New York, Stony Brook, N.Y., b Department of Psychiatry, \\ Wayne State University School of Medicine, Detroit, Mich., 'Department of Medical Genetics, \\ Laboratory of Clinical Neurobiology, New York State Psychiatric Institute, and dDepartment of Psychiatry, \\ College of Physicians and Surgeons, Columbia University, New York, N.Y., USA
}

\section{Key Words}

Schizophrenia $\cdot$ Heart rate variability $\cdot$ Nonlinear complexity analyses · Symbolic dynamics - Vagal function - Sympathetic nervous system - Antipsychotic medication - Cardiac mortality

\begin{abstract}
Objective: Heart rate variability (HRV) reflects functioning of the autonomic nervous system and possibly also regulation by the neural limbic system, abnormalities of which have both figured prominently in various etiological models of schizophrenia, particularly those that address patients' vulnerability to stress in connection to psychosis onset and exacerbation. This study provides data on cardiac functioning in a sample of schizophrenia patients that were either medication free or on atypical antipsychotics, as well as cardiac data on matched healthy controls. We included a medication-free group to investigate whether abnormalities in HRV previously reported in the literature and associated with atypical antipsychotics were solely the effect of medications or
\end{abstract}

This article is dedicated to Michael Blake Ryan in loving memory. whether they might be a feature of the illness (or psychosis) itself. Method: We collected 24-hour ECGs on 19 patients and 24 controls. Of the patients, 9 were medication free and 10 were on atypical antipsychotics. All subject groups were matched for age and gender. Patient groups showed equivalent symptom severity and type, as well as duration of illness. We analyzed the data using nonlinear complexity (symbolic dynamic) HRV analyses as well as standard and relative spectral analyses. $\boldsymbol{R} \boldsymbol{e}$ sults: For the medication-free patients as compared to the healthy controls, our data show decreased R-R intervals during sleep, and abnormal suppression of all frequency ranges, but particularly the low frequency range, which persisted even after adjusting the spectral data for the mean $R-R$ interval. This effect was exacerbated for patients on atypical antipsychotics. Likewise, nonlinear complexity analysis showed significantly impaired HRV for medication-free patients that was exacerbated in the patients on atypical antipsychotics. Conclusions: Altogether, the data suggest a pattern of significantly decreased cardiac vagal function of patients with schizophrenia as compared to healthy controls, apart from and beyond any differences due to medication side effects. The data additionally confirm earlier reports of a deleterious effect of atypical antipsychotics on HRV, which may

\section{KARGER}

(C) 2005 S. Karger AG, Basel

Fax + 41613061234

E-Mail karger@karger.ch

www. karger.com
Accessible online at: www. karger.com/nps
Dr. Mujica-Parodi

Laboratory for the Study of Emotion and Cognition

SUNY Stony Brook School of Medicine, Department of Biomedical Engineering Health Sciences Center T18, Stony Brook NY 11794 (USA)

Tel. +1 631632 1008, Fax +1 631632 8577, E-Mail lilianne.strey@sunysb.edu 
exacerbate an underlying vulnerability in patients. These results support previous evidence that autonomic abnormalities may be a core feature of the illness (or psychosis), and that an even more conservative approach to cardiac risk in schizophrenia than previously thought may therefore be clinically appropriate.

Copyright (C) 2005 S. Karger AG, Basel

\section{Introduction}

Heart rate variability (HRV) is thought to reflect the interplay of the parasympathetic and sympathetic autonomic nervous system (ANS) on the cardiac pacemaker. While regularity of the heart rate is commonly associated with cardiac health, in fact the opposite is true: low HRV predicts a diverse range of cardiac problems, including myocardial infarction [1-3]. The necessity for HRV is a consequence of the externally and internally chaotic environment in which organisms live. The ANS must adapt not only in providing physiological changes necessary for the arousal response, such as increased heart rate, but must also efficiently return to its rest state, reducing unnecessary wear and tear on the body.

Increasingly, concerns about potentially dangerous cardiac side effects of antipsychotic medications have made the examination of HRV in schizophrenia assume clinical importance. Several studies within the past several years appear to implicate atypical antipsychotics, particularly clozapine, with respect to decreased HRV [4-6] and QTc prolongation [7, 8]. However, one common limitation of the HRV studies is that they do not normally include a medication-free group (the study by Agelink et al. [9] is a notable exception having obtained HRV data on a large medication-free patient group, but they used significantly different methods, including 5-min rather than 24-hour sampling). Thus, it is important to determine whether the cardiac effects of medication are the result only of these medications or an underlying vulnerability associated with schizophrenia (or psychosis) itself.

The latter assumes particular relevance because many etiological theories of schizophrenia implicitly or explicitly place critical importance on the role of dysregulation of the limbic system and/or ANS in symptom formation and exacerbation, including hypotheses advanced by $\mathrm{Mu}-$ jica-Parodi et al. [31], Nuechterlein et al. [10], Grossberg [11], and Venables [12]. Studies consistently demonstrate both correlations between the prodrome of schizophrenia and heightened anxiety states [13], as well as the association between relapse in schizophrenia and even minor increases in stress [14]. Research showing patients' elevated cortisol levels and dexamethasone nonsuppression, common hormonal measures of stress, supports the view that a sizeable proportion of patients exhibit significant levels of hyperarousal and impaired inhibition of the arousal response, and that these appear to correlate specifically with psychosis [10]. Finally, physiological studies consistently demonstrate compromised modulation of the sympathetic and parasympathetic nervous system in schizophrenia. For example, up to $50 \%$ of schizophrenia patient samples show abnormalities in pupil reactivity [15], electrodermal activity [16, 17], and orienting responses to novel stimuli [18].

The purpose of this preliminary study was to examine whether HRV might be altered in a medication-free sample of schizophrenia patients, as compared to medicated patients and healthy controls, and thus whether the cardiac differences seen in patients with schizophrenia may be associated with the disease (or psychosis) itself. One unique feature of this study was our use, in addition to the standard spectral analysis, of nonlinear complexity (symbolic dynamic) analysis as a more direct, and therefore perhaps more sensitive, measure of the degree of 'chaos' among $\mathrm{R}-\mathrm{R}$ intervals [19-21].

\section{Methods}

We recruited 19 patients diagnosed with DSM-IV schizophrenia or schizoaffective disorder from the Schizophrenia Research Unit of the New York State Psychiatric Institute. In addition, we recruited 24 age- and gender-matched healthy controls from the Wright State University. For patients, DSM-IV diagnoses were derived from the Diagnostic Interview for Genetic Studies [22]. Of the patients, 9 were medication free, and 10 were treated with atypical antipsychotics (7 clozapine, 3 olanzapine). For ethical reasons, the patients' medication status was a function of treatment choices made by the treating physician and patients, rather than by the researchers. However, post hoc comparison confirmed that there were no significant differences between patient groups with respect to sex, age, or illness duration, nor with respect to the degree of positive or negative symptoms, as determined using the Positive and Negative Syndrome Scale (PANSS) [23]. Demographic and clinical characteristics of the sample are described in detail in tables 1 and 2 . All subjects were physically healthy as indicated by recent physical examinations, laboratory evaluation of complete blood chemistry, thyroid function tests and 12-lead clinical ECGs. No subject had cardiovascular, respiratory, or endocrine illness, current substance abuse, or a history of substance abuse that obscured diagnosis. All participants gave their written informed consent for this study, approved by the Institutional Review Boards of the New York State Psychiatric Institute and the Wright State University.

Subjects wore portable ECG Holter monitors (patients wore Marquette cassette recorders, while controls wore Del Mar Cardiocord- 
Table 1. Demographic variables for subject groups

\begin{tabular}{lllc}
\hline & $\begin{array}{l}\text { Medication- } \\
\text { free }\end{array}$ & Atypical & Control \\
\hline Male & 5 & 6 & 11 \\
Female & 4 & 4 & 13 \\
Caucasian & 4 & 8 & 20 \\
Hispanic & 3 & 2 & 0 \\
Black & 1 & 0 & 4 \\
Asian/Pacific Islands & 1 & 0 & 0 \\
Age, mean \pm SD & $36.5 \pm 11.31$ & $32.83 \pm 9.28$ & $34 \pm 8.1$ \\
\hline
\end{tabular}

ers) over $24 \mathrm{~h}$, and were instructed to conduct their normal activities during this time. We analyzed $20 \mathrm{~h}$ of the subjects' 24 -hour ECG data according to our previous methods [21]. Data recorded on the Holter monitor were then digitized using a Marquette 8000 scanner to derive R-R intervals. Sleep-wake times were confirmed using hourly inspection of $\mathrm{R}-\mathrm{R}$ intervals to detect a sustained drop in heart rate. Any premature ventricular beats, defined as deviating from the previous interval by more than $30 \%$ were eliminated; gaps were filled with an average value in the immediate neighborhood. The edited time series were then sampled at $2 \mathrm{~Hz}$ to obtain the instantaneous heart rate, providing a low-pass filter and allowing an accurate estimation of the power spectrum up to $0.5 \mathrm{~Hz}$, equivalent to a mean breathing rate of 30 breaths per minute. Data were then converted back to R-R intervals, and linearly detrended prior to spectral analyses.

We performed both spectral and nonlinear complexity analyses on the data. For spectral analyses, powers were integrated in the following bands: total power (TP; $0-0.5 \mathrm{~Hz}$ ), ultra-low frequency (ULF; $0-0.0033 \mathrm{~Hz}$ ), very low frequency (VLF; $0.0033-0.04 \mathrm{~Hz}$ ), low frequency (LF; 0.04-0.15 Hz), and high frequency (HF; 0.15-0.5 Hz). To normalize the spectral data with respect to the mean R-R interval, we also calculated relative powers, defined as the ratio of power to TP for each frequency band. As shown below, nonlinear complexity analyses are intrinsically normalized for the mean R-R interval. This method is therefore particularly well suited to evaluate HRV differences between groups with significantly different heart rates.

Research using autonomic blockers has established general guidelines for interpreting the power spectra, although there remains some degree of controversy in separating out the roles of the parasympathetic and sympathetic nervous system, particularly for the LF range. Following the original work of Akselrod et al. [24] and confirmed by later studies [25], the HF range is associated almost entirely with parasympathetic modulation. The LF range is thought to include both sympathetic and parasympathetic components. The VLF is also a marker for sympathetic activity, as well as thermoregulatory processes, peripheral vasomotor activity, and the renin-angiotensin system. The ULF is associated with long-term regulatory mechanisms. The ratio of LF to HF power is considered to correspond with the sympathovagal balance.

Symbolic dynamics, a measure of nonlinear complexity, is based on the principle that complex variability between heart beats can be described by the representation as a consecutive series of R-R inter-
Table 2. Clinical variables for medication group

\begin{tabular}{|c|c|c|c|}
\hline & $\begin{array}{l}\text { Medication- } \\
\text { free }\end{array}$ & \multicolumn{2}{|c|}{ Atypical } \\
\hline & mean SD & mean & $\mathrm{SD}$ \\
\hline Age illness onset & $20.75 \quad 5.28$ & 21.67 & 6.91 \\
\hline Illness duration & 15.7512 .00 & 11.16 & 7.43 \\
\hline Severity of illness PANSS positive & $15.75 \quad 7.90$ & 14.00 & 5.20 \\
\hline Severity of illness PANSS negative & $14.87 \quad 5.02$ & 13.50 & 4.85 \\
\hline
\end{tabular}

val combinations defined with respect to the individual's mean $\mathrm{R}-\mathrm{R}$ interval [19, 20]:

$$
\begin{aligned}
& 0: \quad \mu<t_{n}-t_{n-1} \leq(1+a) \times \mu \\
& 1:(1+a) \times \mu<t_{n}-t_{n-1} \leq \infty \\
& 2:(1-a) \times \mu<t_{n}-t_{n-1} \leq \mu \\
& 3: \quad r \quad 0<t_{n}-t_{n-1} \leq(1-a) \times \mu
\end{aligned}
$$

where $t_{n}-t_{n-1}=R-R$ interval, $\mu=$ mean R-R interval, and $a=0.1$. Each 'word' is composed of four symbols: ' 0 ', ' 1 ', ' 2 ', and ' 3 '. Our adaptation of these techniques [21] defines the 'word count' variable as the percentage of different 'words', out of all 64 combinatorial possibilities, found in an individual's heart rate. Lower word count corresponds with fewer different beat-to-beat sequences, and therefore lower variability.

\section{Results}

As shown in table 3, our ANOVA with the Dunnett two-sided post hoc tests showed that differences between patients and controls were significant for nearly all cardiac variables, that medication-free patients showed cardiac abnormalities, and that these abnormalities were exacerbated in patients on medications. Cardiac variables were unrelated to subdiagnosis (paranoid, disorganized, undifferentiated), sex, ethnicity, or duration of illness. Cardiac variables were also unrelated to specific symptoms, including delusions, disorganization, hallucinations, excitement, grandiosity, hostility, or anxiety (as described by the PANSS), with the one exception of 'suspiciousness and feelings of persecution', which showed a trend correlation with low symbolic dynamic HRV during sleep $(p=0.059)$ and lowered normalized spectral HRV for the HF range $(p=0.070)$.

\section{Medication-Free Patients}

Our sample of medication-free patients showed globally reduced spectral power across all frequencies except 
Table 3. Mean, ANOVA, and post hoc spectral and symbolic dynamic HRV analyses for unmedicated schizophrenia patients, medicated (atypical antipsychotic) schizophrenia patients, and healthy controls

\begin{tabular}{|c|c|c|c|c|c|c|c|}
\hline Variable & $\begin{array}{l}\text { Medication- } \\
\text { free patients } \\
\text { mean }(n=9)\end{array}$ & $\begin{array}{l}\text { Medicated } \\
\text { patients } \\
\text { mean }(n=10)\end{array}$ & $\begin{array}{l}\text { Healthy } \\
\text { controls } \\
\text { mean }(n=24)\end{array}$ & $\mathrm{F}$ & $\mathrm{p}$ & $\begin{array}{l}\text { Post hoc } \\
\text { medication- } \\
\text { free } \times \text { control }\end{array}$ & $\begin{array}{l}\text { Post hoc } \\
\text { medicated } \\
\times \text { control }\end{array}$ \\
\hline \multicolumn{8}{|l|}{20 hours } \\
\hline $\operatorname{lnTP}$ & 8.6 & 7.7 & 9.2 & 16.0 & 0.000 & 0.056 & 0.000 \\
\hline $\operatorname{lnHF}$ & 4.8 & 3.3 & 5.7 & 24.3 & 0.000 & 0.028 & 0.000 \\
\hline $\operatorname{lnLF}$ & 5.5 & 4.3 & 6.6 & 42.7 & 0.000 & 0.000 & 0.000 \\
\hline $\operatorname{lnVLF}$ & 6.4 & 5.2 & 7.2 & 32.6 & 0.000 & 0.009 & 0.000 \\
\hline $\operatorname{lnULF}$ & 8.4 & 7.6 & 8.9 & 11.1 & 0.000 & n.s. & 0.000 \\
\hline Relative HF & 2.6 & 1.4 & 3.6 & 4.1 & 0.025 & n.s. & 0.015 \\
\hline Relative LF & 5.3 & 3.8 & 8.4 & 6.5 & 0.004 & 0.068 & 0.003 \\
\hline Relative VLF & 12.2 & 9.1 & 14.0 & 3.9 & 0.029 & n.s. & 0.016 \\
\hline Relative ULF & 79.8 & 85.7 & 74.1 & 6.8 & 0.003 & n.s. & 0.002 \\
\hline $\mathrm{LF} / \mathrm{HF}$ & 2.5 & 3.3 & 3.0 & 0.4 & n.s. & n.s. & n.s. \\
\hline SymDyn & 32.1 & 29.5 & 40.6 & 9.7 & 0.000 & 0.011 & 0.001 \\
\hline $\mathrm{R}-\mathrm{R}$ interval & 736.489 & 605.117 & 773.609 & 8.8 & 0.001 & n.s. & 0.000 \\
\hline \multicolumn{8}{|l|}{ Awake only } \\
\hline $\ln \mathrm{TP}$ & 8.0 & 7.0 & 8.6 & 22.9 & 0.000 & 0.032 & 0.000 \\
\hline $\ln \mathrm{HF}$ & 4.3 & 2.9 & 5.2 & 18.4 & 0.000 & 0.079 & 0.000 \\
\hline $\operatorname{lnLF}$ & 5.5 & 4.1 & 6.4 & 26.9 & 0.000 & 0.019 & 0.000 \\
\hline $\operatorname{lnVLF}$ & 6.3 & 5.1 & 7.0 & 18.8 & 0.000 & 0.086 & 0.000 \\
\hline $\operatorname{lnULF}$ & 7.6 & 6.6 & 8.1 & 14.6 & 0.000 & n.s. & 0.000 \\
\hline Relative HF & 3.1 & 2.1 & 4.1 & 3.0 & 0.063 & n.s. & 0.042 \\
\hline Relative LF & 8.8 & 7.1 & 13.5 & 3.6 & 0.038 & n.s. & 0.035 \\
\hline Relative VLF & 19.1 & 18.2 & 19.6 & 0.1 & n.s. & n.s. & n.s. \\
\hline Relative ULF & 69.0 & 72.6 & 63.0 & 1.9 & n.s. & n.s. & n.s. \\
\hline $\mathrm{LF} / \mathrm{HF}$ & 4.2 & 3.6 & 3.8 & 0.132 & n.s. & n.s. & n.s. \\
\hline SymDyn & 31.1 & 30.7 & 42.7 & 17.5 & 0.000 & 0.000 & 0.000 \\
\hline $\mathrm{R}-\mathrm{R}$ interval & 707.7 & 585.7 & 723.2 & 5.2 & 0.010 & n.s. & 0.006 \\
\hline \multicolumn{8}{|l|}{ Sleep only } \\
\hline $\operatorname{lnTP}$ & 8.2 & 7.0 & 8.9 & 21.3 & 0.000 & 0.081 & 0.000 \\
\hline $\operatorname{lnHF}$ & 5.6 & 3.6 & 6.0 & 21.1 & 0.000 & n.s. & 0.000 \\
\hline $\operatorname{lnLF}$ & 6.0 & 4.5 & 6.7 & 35.6 & 0.000 & 0.024 & 0.000 \\
\hline $\operatorname{lnVLF}$ & 6.8 & 5.3 & 7.4 & 35.3 & 0.000 & 0.061 & 0.000 \\
\hline $\operatorname{lnULF}$ & 7.5 & 6.5 & 8.1 & 11.1 & 0.000 & n.s. & 0.000 \\
\hline Relative HF & 8.4 & 5.1 & 7.2 & 1.3 & n.s. & n.s. & n.s. \\
\hline Relative LF & 11.3 & 10.3 & 13.3 & 1.0 & n.s. & n.s. & n.s. \\
\hline Relative VLF & 26.7 & 22.4 & 26.4 & 0.6 & n.s. & n.s. & n.s. \\
\hline Relative ULF & 53.6 & 62.2 & 51.7 & 1.3 & n.s. & n.s. & n.s. \\
\hline $\mathrm{LF} / \mathrm{HF}$ & 1.8 & 3.8 & 2.4 & 1.4 & n.s. & n.s. & n.s. \\
\hline SymDyn & 33.1 & 29.5 & 40.6 & 9.1 & 0.001 & 0.033 & 0.001 \\
\hline $\mathrm{R}-\mathrm{R}$ interval & 773.5 & 628.5 & 872.0 & 13.2 & 0.000 & 0.10 & 0.000 \\
\hline
\end{tabular}

SymDyn = Symbolic dynamics.

the ULF range, as compared to healthy controls (nTP: $p=$ 0.056; lnHF: $\mathrm{p}=0.028$; lnLF: $\mathrm{p}=0.000$; lnVLF: $\mathrm{p}=$ 0.009), particularly of the LF range, which includes both sympathetic and parasympathetic components. The mean $\mathrm{R}-\mathrm{R}$ intervals of the medication-free patients were
$11 \%$ shorter than those of the controls during sleep $(\mathrm{p}=$ 0.10 ) and $2 \%$ higher than those of the controls during waking (n.s.). Spectral data normalized for TP showed a relative lowering for schizophrenia patients of the $\operatorname{LF}(\mathrm{p}=$ 0.068) but not HF (n.s.) range. Symbolic dynamic analysis 
of heart rate, intrinsically normalized for the mean $\mathrm{R}-\mathrm{R}$ interval, showed significantly less variability in the $\mathrm{R}-\mathrm{R}$ intervals of the medication-free patients than in those of healthy controls, particularly while awake (awake: $\mathrm{p}=$ 0.000; asleep: $\mathrm{p}=0.033$ ).

\section{Medicated Patients}

The medication-free patients' lowered HRV was further significantly worsened in the patient group treated with atypical antipsychotics, including TP $(\mathrm{p}=0.000)$ as well as all spectra (lnHF: $\mathrm{p}=0.000$; lnLF: $\mathrm{p}=0.000$; $\operatorname{lnVLF}: \mathrm{p}=0.000$; lnULF: $\mathrm{p}=0.000)$. As the medicated patients' 20-hour mean R-R intervals were significantly lowered compared to those of the other groups $(\mathrm{p}=$ 0.000), it was particularly important to further analyze their data using relative spectral powers and symbolic dynamic analysis. Relative ULF, VLF, LF and HF powers were significantly lower in the medicated group compared to healthy controls $(\mathrm{p}=0.015,0.003,0.016$, and 0.002 , respectively). Symbolic dynamic analysis confirmed significantly lowered HRV (awake: $\mathrm{p}=0.000$; asleep: $\mathrm{p}=$ 0.001).

\section{Conclusions}

Our results, using both spectral and symbolic dynamic analyses, show decreased R-R interval variability in medication-free patients compared to healthy subjects, particularly of the LF range, and further significant global decrease in patients with atypical antipsychotics, suggesting a compromised cardiac vagal function in patients with schizophrenia that is exacerbated in patients treated with atypical antipsychotics. When analyzed by subgroups, the presence of these factors in the medication-free patients combined with equivalent symptom severity between the groups suggests that decreased vagal function exists independently of medication side effects, and thus is likely to be associated with the presence of schizophrenia or psychosis itself. The fact that the patients' $\mathrm{R}-\mathrm{R}$ intervals increase far less than the controls' during sleep periods indicates a relative decrease in sympathetic inhibition during sleep, which is consistent with clinical observations of disturbed sleep in this population [26]. However, we found no significant changes in $\mathrm{LF} / \mathrm{HF}$ ratios between the groups for any of the measures.

Interestingly, the autonomic profile demonstrated in schizophrenia is similar to that found in anxiety disorders [27], in which parasympathetic function is affected. A recent study by Okada et al. [28] has also shown a connec- tion between decreased cardiac vagal function and more pronounced psychotic symptoms in patients with schizophrenia. In this context, the significant decreases in linear and nonlinear complexity of $\mathrm{R}-\mathrm{R}$ interval time series in our patient groups may explain in part the association between schizophrenia and increased cardiac mortality. Toichi et al. [29] have also reported similar results linking psychotic symptoms to cardiac parasympathetic dysfunction. The decreased ULF power in medicated, but not medication-free, patients may be important, as the study of Bigger et al. [30] has shown a strong association between decreased ULF power and increased cardiac mortality in patients with cardiac illness.

Post hoc analyses with respect to symptoms, as described by the PANSS, raise intriguing questions as to whether autonomic differences found in schizophrenia may be either attributable to or responsible for the feelings of paranoia common to the illness. Future studies with greater numbers of medication-free patients, capable of greater discrimination with respect to symptom type, may shed valuable light on this issue.

One limitation of our study is the absence, due to clinical considerations, of a repeated-measures design in which every subject is tested off and on medications. Such a design would have tested more directly the question of whether patients improved or deteriorated on cardiac measures according to medication status/type. With our current design, however, the data suggest an even more conservative approach towards cardiac risk than originally thought. If increased cardiac risk in schizophrenia exists independently of medication effects, then cardiac screening and/or monitoring may therefore be appropriate even in the absence of treatment with atypical antipsychotics.

\section{Acknowledgements}

This work was supported by MH01699 K24(D.M.), NARSAD, the G. Harold and Leila Y. Mathers Charitable Foundation and Office of Naval Research Award No. N00014-02-1-0396 (L.R.M.P.). 


\section{References}

$\checkmark 1$ Lombardi F: Clinical implications of present physiological understanding of HRV components. Card Electrophysiol Rev 2002;6:245249.

$>2$ Singh RB, Kartik C, Otsuka K, Pella D, Pella J: Brain-heart connection and the risk of heart attack. Biomed Pharmacother 2002;56(Suppl 2):257s-265s.

$>3$ Tsuji H, Larson MG, Venditti FJ Jr, Manders ES, Evans JC, Feldman CL, Levy D: Impact of reduced heart rate variability on risk for cardiac events. The Framingham Heart Study. Circulation 1996;94:2850-2855.

$\checkmark 4$ Mueck-Weymann M, Rechlin T, Ehrengut F, Rauh R, Acker J, Dittmann RW, Czekalla J, Joraschky P, Musselman D: Effects of olanzapine and clozapine upon pulse rate variability. Depress Anxiety 2002;16:93-99.

$\checkmark 5$ Cohen H, Loewenthal U, Matar M, Kotler M: Heart rate variability in schizophrenic patients treated with antipsychotic agents. Harefuah 2001;140:1142-1147.

6 Rechlin T, Beck G, Weis M, Kaschka WP: Correlation between plasma clozapine concentration and heart rate variability in schizophrenic patients. Psychopharmacology (Berl) 1998; 135:338-341.

$>7$ Czekalla J, Kollack-Walker S, Beasley CM Jr: Cardiac safety parameters of olanzapine: Comparison with other atypical and typical antipsychotics. J Clin Psychiatry 2001;62(suppl 2):3540.

8 Reilly JG, Ayis SA, Ferrier IN, Jones SJ, Thomas SH: QTc-interval abnormalities and psychotropic drug therapy in psychiatric patients. Lancet 2000;355:1048-1052.

-9 Agelink MW, Majewski T, Wurthmann C, Lukas K, Ullrich H, Linka T, Klieser E: Effects of newer atypical antipsychotics on autonomic neurocardiac function: A comparison between amisulpride, olanzapine, sertindole, and clozapine. J Clin Psychopharmacol 2001;21:8-13.

10 Nuechterlein KH, Dawson ME, Gitlin M, Ventura J, Goldstein MJ, Snyder KS, Yee CM, Mintz J: Developmental processes in schizophrenic disorders: Longitudinal studies of vulnerability and stress. Schizophr Bull 1992;18: 387-425.

11 Grossberg S: The imbalanced brain: From normal behavior to schizophrenia. Biol Psychiatry 2000;48:81-98.
12 Venables PH: The Emanuel Miller memorial lecture 1987. Childhood markers for adult disorders. J Child Psychol Psychiatry 1989;30: 347-364.

13 Henmi Y: Prodromal symptoms of relapse in schizophrenic outpatients: Retrospective and prospective study. Jpn J Psychiatry Neurol 1993;47:753-775.

14 Doering S, Muller E, Kopcke W, Pietzcker A, Gaebel W, Linden M, Muller P, Muller-Spahn F, Tegeler J, Schussler G: Predictors of relapse and rehospitalization in schizophrenia and schizoaffective disorder. Schizophr Bull 1998; 24:87-98.

15 Tandon R, Mazzara C, DeQuardo J, Craig KA, Meador-Woodruff JH, Goldman R, Greden JF: Dexamethasone suppression test in schizophrenia: Relationship to symptomatology, ventricular enlargement, and outcome. Biol Psychiatry 1991;29:953-964.

16 Lindstrom LH: Clinical and biological markers for outcome in schizophrenia: A review of a longitudinal follow-up study in Uppsala schizophrenia research project. Neuropsychopharmacology 1996;14(3 suppl):23S-26S.

17 Dawson ME, Schell AM: What does electrodermal activity tell us about prognosis in the schizophrenia spectrum? Schizophr Res 2002; 54:87-93.

18 Bernstein AS, Taylor KW, Starkey P, Juni S, Lubowsky J, Paley H: Bilateral skin conductance, finger pulse volume, and EEG orienting response to tones of differing intensities in chronic schizophrenics and controls. J Nerv Ment Dis 1981;169:513-528.

19 Kurths J, Voss A, Saparin P, Witt A, Kleiner HJ, Wessel N: Quantitative analysis of heart rate variability. Chaos 1995;5:88-94.

20 Voss A, Kurths J, Kleiner HJ, Witt A, Wessel N, Saparin P, Osterziel KJ, Schurath R, Dietz $\mathrm{R}$ : The application of methods of non-linear dynamics for the improved and predictive recognition of patients threatened by sudden cardiac death. Cardiovasc Res 1996;31:419-433.

21 Yeragani VK, Nadella R, Hinze B, Yeragani S, Jampala VC: Nonlinear measures of heart period variability: Decreased measures of symbolic dynamics in patients with panic disorder. Depress Anxiety 2000;12:67-77.
22 Nurnberger JI Jr, Blehar MC, Kaufmann CA, York-Cooler C, Simpson SG, Harkavy-Friedman J, Severe JB, Malaspina D, Reich T: Diagnostic interview for genetic studies. Rationale, unique features, and training. NIMH Genetics Initiative. Arch Gen Psychiatry 1994;51:849_ 859; discussion 863-864.

23 Kay SR, Fiszbein A, Opler LA: The positive and negative syndrome scale (PANSS) for schizophrenia. Schizophr Bull 1987;13:261276.

24 Akselrod S, Gordon D, Ubel FA, Shannon DC, Berger AC, Cohen RJ: Power spectrum analysis of heart rate fluctuation: A quantitative probe of beat-to-beat cardiovascular control. Science 1981;213:220-222.

25 Pagani M, Montano N, Porta A, Malliani A, Abboud FM, Birkett C, Somers VK: Relationship between spectral components of cardiovascular variabilities and direct measures of muscle sympathetic nerve activity in humans. Circulation 1997;95:1441-1448.

26 Benca RM: Sleep in psychiatric disorders. Neurol Clin 1996;14:739-764.

27 Yeragani VK, Sobolewski E, Igel G, Johnson C, Jampala VC, Kay J, Hillman N, Yeragani S, Vempati S: Decreased heart-period variability in patients with panic disorder: A study of Holter ECG records. Psychiatry Res 1998;78: 89-99.

28 Okada T, Toichi M, Sakihama M: Influences of an anticholinergic antiparkinsonian drug, parkinsonism, and psychotic symptoms on cardiac autonomic function in schizophrenia. J Clin Psychopharmacol 2003;23:441-447.

29 Toichi M, Kubota Y, Murai T, Kamio Y, Sakihama M, Toriuchi T, Inakuma T, Sengoku A, Miyoshi K: The influence of psychotic states on the autonomic nervous system in schizophrenia. Int J Psychophysiol 1999;31:147-154.

30 Bigger JT Jr, Fleiss JL, Steinman RC, Rolnitzky LM, Kleiger RE, Rottman JN: Frequency domain measures of heart period variability and mortality after myocardial infarction. Circulation 1992;85:164-171.

31 Mujica-Parodi LR, Corcoran C, Greenberg T, Sackein H, Malaspina D: Are cognitive symptoms of schizophrenia mediated by abnormalities in emotional arousal? CNS Spectr 2002;7: 58-69.

Heart Rate Variability in Schizophrenia 